Research Paper:

\title{
Complications of Subarachnoid Hemorrhage in Patients Admitted to Imam Khomeini Hospital in Urumia
}

Aydin Kazempoor Azar ${ }^{1}$ (D), Mohammad Amin Valizadeh², Javad Aghazadeh', Firooz Salehpoor ${ }^{3}$, Amir Rezakhah ${ }^{1}$, Farhad Mirzaii ${ }^{3}$, Saber Ramezanpoor ${ }^{1}$, Amir Kamalifar ${ }^{1 *}$ (D), Samar Kamalifar ${ }^{4}$, Fereshteh Beygi ${ }^{1}$

1. Department of Neurosurgery, School of Medicine, Nazlou Campus, Urumia University of Medical Sciences, Urumia, Iran

2. Department of Anesthesia and Intensive Care Unit, School of Medicine, Nazlou Campus, Urumia University of Medical Sciences, Urumia, Iran

3. Department of Neurosurgery, School of Medicine, Tabriz University of Medical Sciences, Tabriz, Iran

4. Student Research Committee, Research Deputy, Arak University of Medical Sciences, Arak, Iran



citation Kazempoor Azar A, Valizadeh MA, Aghazadeh J, Salehpoor F, Rezakhah A, Mirzaii F, et al. Complications of Subarachnoid Hemorrhage in Patients Admitted to Imam Khomeini Hospital in Urumia. Iran J Neurosurg. 2018; 4(3):173-178. http://dx.doi. org/10.32598/irjns.4.3.173

http://dx.doi.org/10.32598/irjns.4.3.173

\section{(c) (i) (3)}

Article info:

Received: 21 December 2017

Accepted: 13 April 2018

Available Online: 01 July 2018

Keywords:

Cerebrovascular disorders, Subarachnoid Hemorrhage, Intensive care units

\section{ABSTRACT}

Background and Aim: Secondary complications management of Subarachnoid Hemorrhage (SAH) is one of the therapeutic challenging issues during Intensive Care Unite (ICU) admission. The complications of patients with SAH admitted to the ICU of Imam Khomeini Hospital of Urumia were investigated in this study.

Methods and Materials/Patients: In this descriptive study, the clinical complications of the patients with SAH admitted to ICU including anemia, fever, hyperglycemia, hypertension, electrolyte imbalance, and cardiac arrhythmia were collected from their medical records within a 7-year period. The collected data were analyzed using Chi-squared test and t-test by SPSS.

Results: In total, 483 records of patients with SAH were explored. Moreover, 183 (37.9\%) samples had anemia, 174 (36\%) suffered from fever, 204 (42.2\%) patients were diagnosed with hypertension. A total of 111 (23\%) patients had hyperglycemia, 54 (11.2\%) individuals suffered from sodium disorders. Additionally, 131 (27.1\%) individuals had cardiac arrhythmias.

Conclusion: The obtained results suggested that the most prevalent complications following SAH are hypertension, anemia and fever. Furthermore, there was a significant correlation between cardiac arrhythmias, as well as sodium and hyperglycemia disorders, and the treatment outcome of patients. Patients admitted to ICU should be under intensive care to reduce the mortality rate associated with SAH.

\section{* Corresponding Author:}

Amir Kamalifar, MD.

Address: Department of Neurosurgery, School of Medicine, Nazlou Campus, Urumia University of Medical Sciences, Urumia, Iran

Tel: +98 (914) 1534548

E-mail:amirkamalifar@gmail.com 


\section{Highlights}

- The most prevalent medical complications of subarachnoid hemorrhage are fever, anemia, hypertensive state, hyperglycemia, sodium imbalance, and cardiac arrhythmia.

- This complication can increase mortality and morbidity of the patients.

\section{Plain Language Summary}

Subarachnoid hemorrhage is a complicated situation and can be worsened by many factors like fever, anemia, cardiac arrhythmia, and sodium imbalance. Should the clinician control these complications the mortality and morbidity of the patients will significantly reduce.

\section{Introduction}

ub-arachnoid Hemorrhage (SAH) usually occurs as a result of a ruptured brain aneurysm or a spontaneous arterialvenous malformation. The onset of symptoms is sudden in SAH and always accompanied by a typically severe but not irreversible headache. Often at the onset, consciousness is transiently or permanently lost; in this case, decerebrate posturing or rare seizures are likely to occur. Approximately $5 \%$ of autopsied people experienced brain aneurysms without any rupture symptoms.

Hypertension (HTN) has not been identified as the definite underlying cause of aneurysm formation. However, acute blood pressure elevation can be responsible for ruptured brain aneurysms. Fusiform aneurysms result from the peripheral expansion of the body of a brain artery. Contrary to saccular aneurysms, these aneurysms are hypothetically caused by atherosclerosis or dissection. The main complications of aneurysm rupture include death, recurrent intracerebral hemorrhage and vasospasm, seizure (10\%), acute and chronic hydrocephalus, and intracranial hematoma [1].

Complications that may occur following SAH include hyperglycemia, hyponatremia and hypernatremia, fever and pneumonia, hypotension, hypertension, pulmonary edema, and heart arrhythmia [2, 3]. Frontera JA et al. examined post-SAH hyperglycemia and predicted subsequent complications and its effect on the treatment outcomes. GB average was defined as the average maximum daily blood glucose level of $5.8 \mathrm{mmol} / \mathrm{L}$ (105 $\mathrm{mg} / \mathrm{dL}$ ). The results indicated that the measured GB average was $1.8 \mathrm{mmol} / \mathrm{L}$ (33 $\mathrm{mg} / \mathrm{dL}$ ).
The post-SAH hyperglycemia was associated with serious hospital complications and increased hospitalization time in ICU and the increased risk of death or serious disabilities [4]. Dorhout Mees SM et al. conducted a study on fever following aneurismal SAH and its association with the development of hydrocephaly and bleeding. Their results revealed that intra-ventricular blood volume was an independent risk factor for fever. In this study, non-infectious fever was rare and unrelated to blood extracted from the veins and hydrocephaly [5].

Ke et al. reported that fever, anemia, hyperglycemia, hypoxia, and hypertension can increase mortality and morbidity following $\mathrm{SAH}$; an intensive management of these factors can decrease the mortality and morbidity rates in this regard [6]. Frontera et al. investigated cardiac arrhythmias after $\mathrm{SAH}$, the associated risk factors and its effect on the treatment outcomes. Their results revealed that significant clinical arrhythmias, which are often Atrial Fibrillation (AF) and abundant, occurred in $4 \%$ of the patients. Cardiac arrhythmias after SAH are associated with an increased risk of comorbidities with other cardiovascular problems, prolonged hospitalization and unpleasant treatment outcomes or death [7].

Sampson et al. examined the factors associated with the spread of anemia after SAH. They concluded that it is possible to predict anemia with the use of basic clinical variables. Anemia is highly associated with surgery, which is largely justifiable due to blood loss and high systematic inflammatory response (through cytokines that inhibit RBC production) [8].

Matthew et al. conducted a survey on the association of cerebral natriuretic peptide serum with hypernatremia and delayed ischemic neurological deficit after $\mathrm{SAH}$. The results showed that an increase in serum BNP level, which is independently related to hypernatremia and 
a significant increase in delayed neurological disorder in 24 hours after the disease onset can predict GCS in patients for two weeks; and the level of BNP can be a prognostic indicator for delayed neurological deterioration and increased mortality rate [9].

\section{Methods and Materials/Patients}

The present cross-sectional descriptive study explored the clinical records of patients with nontraumatic SAH admitted to Imam Khomeini Hospital in Urumia City, Iran. The statistical population and sample size of the study were patients with SAH admitted to the ICU of Imam Khomeini Hospital of Urumia from 2010 to 2017.

Demographic characteristics (age and sex) of the patients, evidence related to all the defined complications of SAH, including anemia, fever, hyperglycemia, hypertension, sodium disorders and cardiac arrhythmia were collected and recorded in a researcher-made datasheet. The obtained data were analyzed using SPSS.

\section{Results}

In this study, 500 clinical records of the patients with SAH admitted to ICU (2010-2017) were investigated. Moreover, 10 patients due to equal GCS, 4 patients due to transfer to other medical centers, and 3 individuals due to incomplete medical records were excluded from the study. We reviewed 483 cases, eventually. Of the 483 patients with $\mathrm{SAH}, 309$ (64\%) were male and 174 (36\%) were female (Figure 1). The patients' Mean \pm SD age was $49.19 \pm 5.2$ years (age range: $3-82$ years) .

This study only included brain CT angiography reports of 438 nontraumatic SAH patients (Table 1). Considering the aneurysmal location, size, GCS, and the general condition of patients' microsurgical aneurysm clipping, endovascular intervention, and conservative treatment were recorded (Table 2). The obtained results revealed that out of 483 patients with $\mathrm{SAH}, 183$ (37.9\%) individuals had anemia and 300 (62.1\%) patients had no anemia. Fever was recorded in 174 (36\%) patients, 204 (42.2\%) individuals had hypertension, and hyperglyce-



Figure 1. The number of patients with SAH in respect of gender

Table 1. The number of brain $\mathrm{CT}$ angiography findings in the studied patients

\begin{tabular}{ccc}
\hline & No. (\%) & \\
\hline Aneurysmal & Non-aneurismal \\
\hline $346(78.99)$ & $92(21)$ \\
\hline
\end{tabular}

Table 2. The intervention modality in the patients with a positive report of aneurysms based on brain CT angiography

\begin{tabular}{cc}
\hline Intervention Modality & No. (\%) \\
\hline Microsurgery clipping & $154(44.5)$ \\
Endovascular & $85(24.5)$ \\
Conservative & $107(30.09)$
\end{tabular}


Table 3. Complication frequency in the study groups

\begin{tabular}{|c|c|c|c|}
\hline Complication & Positive & Negative & Total \\
\hline Anemia & 183 & 300 & 483 \\
\hline Fever & 174 & 309 & 483 \\
\hline Hypertension & 204 & 279 & 483 \\
\hline Hyperglycemia & 111 & 372 & 483 \\
\hline Sodium imbalance & 54 & 429 & 483 \\
\hline Cardiac arrhythmia & 131 & 352 & 483 \\
\hline
\end{tabular}

Table 4. The relationship between the patients' treatment outcomes and SAH in respect of the study variables

\begin{tabular}{|c|c|c|c|c|c|}
\hline \multirow{2}{*}{ Complication } & \multirow{2}{*}{ Treatment Outcome } & \multicolumn{3}{|c|}{ No. (\%) } & \multirow{2}{*}{$\mathbf{P}$} \\
\hline & & With Fever & Without Fever & Total & \\
\hline \multirow{3}{*}{ Anemia } & Discharge & $108(38.4)$ & $173(61.6)$ & $281(100)$ & \multirow{3}{*}{0.42} \\
\hline & Death & $75(37.1)$ & $127(62.9)$ & $202(100)$ & \\
\hline & Total & 183(37.9) & $300(62.1)$ & $483(100)$ & \\
\hline \multirow{3}{*}{ Fever } & Discharge & $93(33.1)$ & 188(66.9) & $281(100)$ & \multirow{3}{*}{0.06} \\
\hline & Death & $81(40.1)$ & $121(59.9)$ & $202(100)$ & \\
\hline & Total & $174(36)$ & $309(64)$ & $483(100)$ & \\
\hline \multirow{3}{*}{ Hypertension } & Discharge & $93(33.1)$ & $188(66.9)$ & $281(100)$ & \multirow{3}{*}{0.36} \\
\hline & Death & $81(40.1)$ & $121(59.9)$ & 202(100) & \\
\hline & Total & $174(36)$ & $309(64)$ & $483(100)$ & \\
\hline \multirow{3}{*}{ Sodium disorders } & Discharge & $24(8.5)$ & $257(91.5)$ & 281(100) & \multirow{3}{*}{0.001} \\
\hline & Death & $30(14.9)$ & $172(85.1)$ & $202(100)$ & \\
\hline & Total & $54(11.2)$ & $429(88.8)$ & $483(100)$ & \\
\hline \multirow{3}{*}{ Hyperglycemia } & Discharge & $46(16.4)$ & $235(83.6)$ & $281(100)$ & \multirow{3}{*}{0.001} \\
\hline & Death & $65(32.2)$ & $137(67.8)$ & 202(100) & \\
\hline & Total & $111(23)$ & $372(77)$ & $483(100)$ & \\
\hline \multirow{3}{*}{ Cardiac arrhythmia } & Discharge & $24(8.5)$ & $257(91.5)$ & $281(100)$ & \multirow{3}{*}{0.001} \\
\hline & Death & $30(14.9)$ & $172(85.1)$ & $202(100)$ & \\
\hline & Total & $54(11.2)$ & $429(88.8)$ & 483(100) & \\
\hline
\end{tabular}


mia was detected in 111 (23\%) patients. Sodium leve was explored in respect of hypo- and hypernatremic states only in 54 (11.2\%) patients. Moreover, the cardiac rhythm was only reported in 131 (27.1\%) patients with cardiac arrhythmia (Table 3).

Of 483 patients with SAH, 281 (58.2\%) individuals survived and 202 (41.8\%) died. Investigating the treatment outcomes of patients with anemia revealed that 108 (38.4\%) out of 281 discharged patients suffered from anemia and 173 (61.6\%) individuals had no anemia, and $75(37.1 \%)$ individuals out of 202 dead patients demonstrated the symptoms of anemia and 127 (62.9\%) individuals did not. Chi-squared test results presented no significant correlation between the treatment outcome of patients and anemia ( $\mathrm{P}=0.42)$.

Analysis of patients' fever and treatment outcomes suggested that out of 281 patients, 93 (33.1\%) individuals had a fever and 188 (66.9\%) individuals had no fever, and out of 202 dead patients, 81 (40.1\%) had a fever, while 121 (59.9\%) patients had no fever. ChiSquared test showed no significant relationship between the treatment outcomes of patients and fever $(P=0.06)$. Additionally, we calculated that the $P$ equal to 0.36 for the relation between hypertension and $\mathrm{SAH}$; however, statistical analysis suggested a significant relationship between hyperglycemia arrhythmia and sodium disorders $(\mathrm{P}<0.05)$ (Table 4$)$.

\section{Discussion}

Pre-existing comorbidities in ICU patients such as high blood glucose, low $\mathrm{O} 2$ saturation, electrolytes imbalance and the disruption of acid-base buffers after a surgical intervention can aggravate the patient's clinical condition and increase the mortality rate in them. Thus, all patients should be admitted to ICU after surgery, and under the neurocritical care of trained staff. The obtained results revealed that fever, anemia, and hyperglycemia have had the highest impact on the patients' mortality after SAH. Therefore, the findings are consistent with the study by Qureshi AI [9-13].

The present study also recommends reviewing clinical trials for targeted interventions to prevent and treat commonly occurring complications after SAH. Findings of Frontera JA et al. correlate with the findings of this study on the increased risk of death; and cardiac arrhythmia has a significant relationship with mortality after SAH [7]. However, in terms of the duration of hospitalization in ICU, it is not comparable with the present study. The duration of admission in ICU has not been studied in this study.

The study by Sampson et al. suggested the possibility of predicting anemia onset with the use of basic clinical variables [8]; they also reported that severe anemia as the result of surgery is mostly caused by blood loss and high systemic inflammatory response (through cytokines that inhibit RBC production) is justifiable. This data is consistent with the view that anemia was among the most frequent complications in the studied patients. In addition, GCS is not an appropriate indicator to evaluate the neurological status in patients admitted to ICU due to paralysis or sedative medication use [14-18].

Roviro et al. in a cohort study on 334 patients with $\mathrm{SAH}$ reported associating factors with poor treatment outcomes; high mortality rate was correlated with $>65$ years of age, female sex, systolic blood pressure of $>180$ $\mathrm{mmHg}$, rebleeding, vasospasm, cerebral ischemia, hyperglycemia in the first day of hospital admission, and WFNS of grades 4-5. Studies failed to determine the prognostic index with $100 \%$ sensitivity and specificity to predict mortality and morbidity rates in SAH [19]. We disregarded determining the prognostic value of indicators. Furthermore, some data may be missed while data recording. Another limitation of our data regarded the lack of including data of the ICU patients and patients admitted to general neurosurgery ward.

\section{Conclusion}

The obtained results suggested that the most prevalent clinical complications after SAH are anemia, hyperglycemia, sodium disorders, and cardiac arrhythmia; and out com of the patients depend on them. The presence of anemia in patients after SAH can be associated with surgery that requires further investigations. Future evaluation of the prognostic value of this indicator on the treatment outcomes of patients are necessary.

\section{Ethical Considerations}

\section{Compliance with ethical guidelines}

The current study was approved by the Ethics Committee of Urumia University of Medical Sciences (Code: ir.umsu.ac.rc.1395.420).

\section{Funding}

This article was supported by Urumia University of Medical Sciences. 


\section{Authors' contributions}

All authors contributed in designing, running, and writing all parts of the research.

\section{Conflict of interest}

The authors declare no conflict of interest.

\section{Acknowledgments}

We really appreciate Fooziyeh Samadi for reviewing this article.

\section{References}

[1] Aminoff MJ, Greenberg DA, Simon RP. Headache \& facial pain. In: Aminoff MJ, Greenberg DA, Simon RP, editors. Clinical Neurology. Pennsylvania: McGraw-Hill Education; 2015.

[2] Souter MJ, Lam AM. Neurocritical care. In: Miller RD, Cohen $\mathrm{NH}$, Eriksson LI, Fleisher LA, Wiener, Kronish JP, et al., editors. The Text Book of Miller's Aneshthesia. Amsterdam: Elsevier; 2015

[3] Wartenberg KJ, Schmidt JM, Claassen J, Temes RE, Frontera JA, Ostapkovich N. Impact of medical complications on outcome after subarachnoid hemorrhage. Critical Care Medicine. 2006, 34(3):617-23. [DOI:10.1097/01.CCM.0000201903.46435.35] [PMID]

[4] Frontera JA, Fernandez A, Claassen J, Schmidt M, Schumacher HC, Wartenberg K. Hyperglycemia after SAH: Predictors, associated complications, and impact on outcome. Stroke. 2006 37(1):199-203. [DOI:10.1161/01.STR.0000194960.73883.0f] [PMID]

[5] DorhoutMees SM, Luitse MJA, Bergh WM, Rinkel GJ. Fever after aneurysmal subarachnoid hemorrhage relation with extent of hydrocephalus and amount of extravasated blood. Stroke. 2008, 39(7):2141-3. [DOI:10.1161/STROKEAHA.107.509851] [PMID]

[6] Wartenberg KE, Mayer SA. Medical complications after subarachnoid hemorrhage: New strategies for prevention and management. Current Opinion in Critical Care. 2006; 12(2):78-84 [DOI:10.1097/01.ccx.0000216571.80944.65] [PMID]

[7] Frontera JA, Parra A, Shimbo D, Fernandez A, Schmidt JM, Peter $\mathrm{P}$, et al. Cardiac arrhythmias after subarachnoid hemorrhage: Risk factors and impact on outcome. Cerebrovascular Diseases. 2008, 26(1):71-8. [DOI:10.1159/000135711] [PMID] [PMCID]

[8] Sampson TR, Dhar R, Diringer MN. Factors associated with the development of anemia after subarachnoid hemorrhage. Neurocritical Care. 2010; 12(1):4-9. [DOI:10.1007/s12028-009-9273-1] [PMID] [PMCID]

[9] McGirt MJ, Blessing R, Nimjee SM, Friedman AH, Alexander MJ, Laskowitz DT, et al. Correlation of serum brain natriuretic peptide with hyponatremia and delayed ischemic neurological deficits after subarachnoid hemorrhage. Neurosurgery. 2004; 54(6):1369-74 [DOI:10.1227/01.NEU.0000125016.37332.50] [PMID]

[10] Ting HW, Chen MS, Hsieh YC, Chan CL. Good mortality prediction by Glasgow Coma Scale for neurosurgical patients.
Journal of the Chinese Medical Association. 2010; 73(3):139-43. [DOI:10.1016/S1726-4901(10)70028-9]

[11] Gruber A, Reinprecht A, Illievich UM, Fitzgerald R, Dietrich $\mathrm{W}$, Czech T, et al. Extracerebral organ dysfunction and neurologic outcome after aneurysmal subarachnoid hemorrhage. Critical Care Medicine. 1999; 27(3):505-14. [DOI:10.1097/00003246199903000-00026]

[12] Claassen J, Vu A, Kreiter KT, Kowalski RG, Du EY, Ostapkovich $\mathrm{N}$, et al. Effect of acute physiologic derangements on outcome after subarachnoid hemorrhage. Critical Care Medicine. 2004 32(3):832-8. [DOI:10.1097/01.CCM.0000114830.48833.8A]

[13] Qureshi AI, Suri MF, Sung GY, Straw RN, Yahia AM, Saad $\mathrm{M}$, et al. Prognostic significance of hypernatremia and hyponatremia among patients with aneurysmal subarachnoid hemorrhage. Neurosurgery. 2002; 50(4):749-56. [DOI:10.1097/00006123200204000-00012]

[14] Samuels O, Webb A, Culler S, Martin K, Barrow D. Impact of a dedicated neurocritical care team in treating patients with aneurysmal subarachnoid hemorrhage. Neurocritical Care. 2011; 14(3):334-40. [DOI:10.1007/s12028-011-9505-z] [PMID]

[15] Frontera JA, Fernandez A, Claassen J, Schmidt M, Schumacher HC, Wartenberg K, et al. Hyperglycemia after SAH: Predictors, associated complications, and impact on outcome. Stroke. 2006 37(1):199-203. [DOI:10.1161/01.STR.0000194960.73883.0f] [PMID]

[16] Rosengart AJ, Schultheiss KE, Tolentino J, Macdonald RL. Prognostic factors for outcome in patients with aneurysmal subarachnoid hemorrhage. Stroke. 2007; 38(8):2315-21. [DOI:10.1161/ STROKEAHA.107.484360] [PMID]

[17] Langham J, Reeves BC, Lindsay KW, van der Meulen JH, Kirkpatrick PJ, Gholkar AR, et al. Variation in outcome after subarachnoid hemorrhage: A study of neurosurgical units in UK and Ireland. Stroke. 2009; 40(1):111-8. [DOI:10.1161/STROKEAHA.108.517805] [PMID]

[18] Kurtz P, Claassen J, Helbok R, Schmidt JM, Fernandez L, Presciutti M, et al. Systemic glucose variability predicts cerebral metabolic distress and mortality after subarachnoid hemorrhage: A retrospective observational study. Critical Care. 2014; 18(3):R89. [DOI:10.1186/cc13857] [PMID] [PMCID]

[19] Rodríguez DR, Matamoros CS, Cúe LF, Hernández JM, Sánchez YP, Nellar JP. Factors associated with poor outcome for aneurysmal subarachnoid haemorrhage in a series of 334 patients. Neurología. 2017; 32(1):15-21. [DOI:10.1016/j.nrleng.2014.12.016] 